\title{
THE LIMITS OF LEADERSHIP AS A BARRIER TO QUALITY ASSURANCE IN HIGHER EDUCATION IN ALGERIA
}

\author{
Wissam BELIMANE ${ }^{1 *}$, Amina CHAHED ${ }^{2}$ \\ ${ }^{1}$ LIMGE Lab, National High School of Management ENSM, Kolea, Algeria \\ ${ }^{2}$ National High Veterinary School ENSV, Algiers, Algeria \\ "Corresponding author's e-mail: w.belimane@ensm.dz
}

\begin{abstract}
Since 2010, Quality Assurance (QA) has been officially adopted and has become a priority of the Higher Education (HE) system in Algeria. This study is part of this framework and aims to explore the role of leadership in the QA process as perceived by Quality Management Managers (QMRs). It is based on a qualitative approach through interviews with 27 QMRs from different institutions. Content analysis technique was used to analyse data.

The results show that QMRs consider the lack of commitment and involvement of institutions' higher management as a major constraint to the success of quality processes. The study reveals that the main barrier to QA is related to the limitations of institutions' governance, which do not promote autonomy and effectiveness. The study suggests that two elements seem to be crucial: autonomy and training/awareness of institutions' higher managers. Those elements are closely linked and could be at the origin of the success or failure of quality mechanisms.
\end{abstract}

Keywords: Higher Education Institutions (HEIs), Leadership, Perception, Quality Assurance (QA), Quality Assurance Managers (QAMs)

JEL Classification: I230

\section{INTRODUCTION}

Higher Education Institutions (HEIs) around the world are evolving in a very dynamic and turbulent environment that requires adaptation and evolution of practices. The massification of Higher Education (HE), new forms of governance, new technologies, and graduates' employability are the main challenges facing academic institutions (Campbell \& Rozsnyai, 2002; Harvey \& Newton, 2004; Roskosa \& Stukalina, 2018). All of these elements have prompted a greater call for Quality Assurance (QA) in order to prepare institutions to better meet the expectations of their environments.

In Algeria, the LMD system (Licence-Master-Doctorate) was officially adopted in 2003 and implemented in HEIs from 2004. This major reform made QA an essential component and a priority of the HE system. However, it was not until 2010 that the HE sector put in place the structures, conditions, and organisation of a QA system. The first focus was on Internal Quality Assurance (IQA), which referred to intra-institutional practices aimed at quality controlling and improving from within the institution (Hou et al., 2015; Nguyen, 2016). As for External Quality Assurance 
(EQA), which is based on peer review (Westerheijden, 2007), it is still under development.

In 2017, the HEIs received instructions from the supervisory authority (Ministry of Higher Education and Scientific Research - MESRS) to lay the foundations of an IQA system through self-assessment of their practices according to the quality national standard. This instruction obliged the institutions to review their goals, redefine their practices and commit resources.

These dynamic changes require the commitment and involvement of the institutions' higher managers. By higher managers we mean the first institutions' heads (rectors or directors), vice-rectors, deputy directors and deans of faculties. They are both practitioners and managers of QA from the top (Pham \& Starkey, 2016). Their role as quality initiators and leaders is considered an important factor for the adoption and implementation of QA in universities (Mulu, 2012).

However, the HE system in Algeria is characterised by a high level of centralization (World Banque, 2012). Government control is applied to all aspects of public institutions' management and organisation. We therefore suppose that implementing QA in this specific context, which reduces the decision-making power and autonomy, is a challenge for all institutions.

The main aim of this article is to reveal the obstacles related to leadership in the QA implementation process. The basic idea is to explore the perceptions of those most involved in the IQA process, namely the QAMs. The research question is: How is the involvement of institutions' managers perceived in $Q A$ implementation process?

This article begins with a literature review, followed by a brief presentation of the QA context in Algeria. Then, it presents the methodology adopted. The results will be presented and discussed in the final section that precedes the general conclusion.

\section{LITERATURE REVIEW}

In the literature, there is a lack of consensus on a single, common and complete definition of quality in HE. The concept is dynamic (Welzant et al., 2015), and interpreted differently by different stakeholders (Elassy, 2015; Pham \& Starkey, 2016; Saurbier, 2020). In simple terms, everyone associates quality with what they expect from the institution.

Martin and Stella explained that a single definition was not appropriate for all HE goals as teaching and learning, research and management (Martin \& Stella, 2007). However, there have been some attempts to define the concept. Some are general, but can be adapted and transposed to the education sector. Others are directly specific to its goals. For the purposes of the present research, we borrow the following definition from the CINDA (Inter-University Development Centre/ Chile) which seems to be complete and highlights the two essential QA goals: "Quality is a concept that considers above all the capabilities of an institution or program to meet external expectations and internal goals, by organising its processes in a coherent way to achieve the intended goals" (according to the CINDA study, referred in (Torre \& Zapata, 2012). 
QA in HE is therefore related to the satisfaction of two main goals, i.e., the first one is internal, related to the satisfaction of internal expectations, and the second one is external, related to the satisfaction of external standards. HEIs need strong leadership to guide them toward achieving these goals. The literature has demonstrated a strong interdependence between QA success and leadership in HE (O'Mahony \& Garavan, 2012; Seyfried \& Pohlenz, 2018).

Leadership is the management ability to direct and guide the organisation's actors toward goal achievement, and does so by motivating rather than constraining them. For Bryman, it is a "process of social influence by which a leader directs members of a group towards a goal" (Bryman, 1992). According to Zumitzavan and Michie, leadership is "the leaders' ability to encourage their members to perform above their normal level of effort, which ultimately can help improve organizational performance" (Zumitzavan \& Michie, 2015).

For the purpose of this study, leadership refers to the commitment of HEI higher managers in QA implementation process. This commitment should not be limited to simple management roles, but rather extend to other more important activities, such as defining a vision, setting clear goals, allocating adequate resources, and motivating and encouraging staff.

\subsection{Visible Commitment}

Management must make a visible and voluntary commitment to quality through explicit actions. The other organisation' actors will follow their leaders and will only commit to the QA process when they see their active participation (Mishra \& Pandey, 2013/2).

Commitment is the means of convincing staff that management is not only serious about the QA process, but is also willing to be involved in its implementation. Management commitment must be continually demonstrated, and tested until it becomes an integral part of change, and thus people can relate to its benefits (Ritchie \& Dale, 2000). According to Ahmed et al. (2003), after management commitment, the order of representation is not important, since most of the factors can run concurrently (Ahmed, Yang, \& Dale, 2003).

\subsection{Clear Goal Setting}

As stated above, leadership is an influence process that leads to goal achievement. The leader must therefore start by defining a vision and policy, setting clear goals, and then pushing other actors to achieve them. O'Mahony and Garavan state that a clear policy provides a strong and consistent framework for effective leadership that sets expectations and guides the actions of all stakeholders (O'Mahony \& Garavan, 2012).

\subsection{Motivation and Recognition}

Motivation is one of the dimensions of institutional leadership that influence QI practices (Middlehurst, 1997). It can be either material or professional. The former relates to additional funding for new assignments, and the latter relates to 
reorientation and career development, particularly for academic staff. These two categories, which are not necessarily mutually exclusive strategies, can lead to considerable overlap (Gordon \& Whitchurch, 2007). According to the latter authors, any system that does not provide for these two categories of incentives will face particular challenges.

\subsection{Resource Allocation}

The QA process involves the investment of a substantial quantity of resources (material, economic, human, etc.). QA must involve training of actors, bringing in external expertise, organising events, and conducting surveys of a large population. This involves high costs, effort and time (Koch \& Fisher, 1998). However, given that HEIs are primarily funded by the government (Venkatraman, 2007), the resources allocated may not be sufficient to carry out the QA experiment.

The role of management is therefore related to its commitment to provide inspired guidance, and effective deployment of human and technical resources to achieve greater productivity (Sayeda, Rajendran, \& Lokachari, 2010).

\subsection{Definition of Mission and Responsibilities}

The mission and responsibilities assigned to organisation's actors designated to implement QA must be formalized and clearly defined in order to legitimize their role. Thus, they should have a visible position in the organisation that reflects a clear hierarchical status (Scharager Goldenberg, 2017).

All of the activities elicited can be grouped into the three dimensions: the conceptual and analytical dimension, the structural and systemic dimension, and the motivational and behavioural dimension (Middlehurst, 1997). According to the author, these dimensions should be linked, but all often are not. The first dimension involves an ability to create a vision, to think in new ways, and to generate and exchange new ideas (Middlehurst, 1997). Leaders must have a vision and set clear and consistent goals. Thus, they must be the first to commit to that vision, and to communicate it to all staff in order to ensure their commitment and support.

The second dimension involves restructuring and redefining functions and activities to improve staff and organisational performance, and to respond effectively to external and internal changes. The systemic part of this dimension consists of paying attention to all the elements that impact performance and functioning of the institution. In practical terms, taking a system perspective involves identifying stakeholders and their interests, searching for partnerships and collaborative opportunities, and monitoring performance at all levels (Nguyen, 2016).

The final dimension of leadership involves motivating staff to facilitate change. For the behavioural aspect, Middlehurst states that change is likely to be accepted and more profitable if it is based on partnership and trust rather than control and policing (Middlehurst, 1997). 


\section{CONTEXT OF QUALITY ASSURANCE IN HIGHER EDUCATION IN ALGERIA}

The QA project in Algeria was concretized in 2010 by the creation of Commission for the Implementation of Quality Assurance in Higher Education (CIAQES). The first action taken by it was to appoint QAMs, and to set up Quality Assurance Units (QAUs) in all institutions, made up of members representing various educational and administrative structures. The second action consisted in the training of QAMs with the aim that they could become trainers for other members of their units.

During 2014, the National Reference for Quality Assurance in Higher Education (RNAQES) was developed. It describes the guidelines for QA implementation and is a fundamental tool for carrying out quality assessment activities. The national standard is organised in seven (07) major domains that touch on all $\mathrm{HE}$ institutional and functional aspects. Each domain is broken down into fields, references, criteria and evidence. The governance domain is the first one with 27 references, covering fifty-three (53) assessment criteria. This represents $24 \%$ of all criteria of the standard, and demonstrates the important role given to institutional management and leadership.

In 2017, quality self-assessment was launched in all institutions following instruction from the supervisory authority. The work was assigned to the SelfAssessment Committees (SAC) created for this purpose, and worked in collaboration with the QAUs. In what follows, the term "Project Teams" will be used to refer to the members of both the QAUs and the SACs.

In 2018, HEIs were required to develop institutional projects that would define policies and strategies for the institutions' development in different areas. These projects were to be based on self-assessment results and recommendations, and organised around the national standard areas.

\section{RESEARCH DATA AND METHODOLOGY}

\subsection{Target Population}

Institutions' QAMs who led QA and self-assessment project were the target population for this study. We assumed that they were the first actors who experienced barriers in the process; therefore, they could provide relevant information on the topic.

\subsection{Method}

This research follows a qualitative method approach through interviews in a group setting. Interviews were conducted by region (East, West, and Central).

We took part as trainers in training sessions organised by the CIAQES in favour of HEI QAMs (sessions scheduled in its roadmap for 2019). This opportunity justifies the choice of group-interview method. We took advantage that the QAMs were all gathered in training sessions to organise the interviews. 
The groups were composed of 14 QAMs (Eastern session) and 9 QAMs (Western Session). However, due to the health crisis in 2020 (Covid19), the central session could not be conducted. To this end, individual interviews were conducted with 4 central region's QAMs. This number was considered sufficient by referring to the criterion of information redundancy (Ary et al., 2014) because no new information was communicated.

The interviews focused on the main difficulties faced in relation to the involvement of institutions' managers in QA implementation process. The discussions lasted approximately one hour during which the participants provided testimonies that highlighted their real experiences and views. We (both authors) acted as facilitators. We asked questions, framed discussions and encouraged interaction between the QAMs.

Table 1. Summary of the Interviews

\begin{tabular}{|c|c|c|c|c|c|c|}
\hline Region & $\begin{array}{c}\text { Interview } \\
\text { type }\end{array}$ & $\begin{array}{c}\text { Interviewees } \\
\text { number }\end{array}$ & Dates & Duration & Mean & $\begin{array}{c}\text { Transcribed } \\
\text { pages }\end{array}$ \\
\hline East & $\begin{array}{c}\text { Group } \\
\text { interview }\end{array}$ & 14 QAMs & $18 / 02 / 19$ & $60 \mathrm{~min}$ & Note taking & 3 \\
\hline \multirow{2}{*}{ West } & $\begin{array}{c}\text { Group } \\
\text { interview }\end{array}$ & \multirow{2}{*}{ 9 QAMs } & $31 / 10 / 19$ & $60 \mathrm{~min}$ & Note taking & 2 \\
\hline \multirow{2}{*}{ Central } & \multirow{2}{*}{$\begin{array}{l}\text { Individual } \\
\text { interviews }\end{array}$} & \multirow{2}{*}{4 QAMs } & $18 / 10 / 20$ & $30 \mathrm{~min}$ & Recording & 2 \\
\cline { 3 - 7 } & & $18 / 11 / 20$ & $30 \mathrm{~min}$ & Note taking & 1 \\
\cline { 3 - 7 } & & $29 / 11 / 20$ & $30 \mathrm{~min}$ & Recording & 2 \\
\hline \multicolumn{2}{|c|}{ Total } & $\mathbf{2 7}$ QAMs & $\mathbf{- -}$ & $\mathbf{4 h 1 5} \mathbf{m i n}$ & -- & $\mathbf{1 2}$ pages \\
\hline
\end{tabular}

Source: Developed by the authors

As shown in Table 1, a total of 27 QAMs participated in this qualitative study.

\subsection{Data Analysis}

Data were analysed through qualitative content analysis using the following approach:

\section{Transcript}

Reading

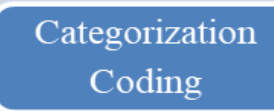

Categorization
Coding

Coding

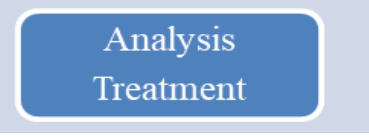

Analysis
Treatment
Results

Interpretation

Fig. 1. Steps of the qualitative content analysis (developed by the authors).

Transcription consists in the transformation of an oral speech into text (Bardin, 1977). As part of our study, QAMs recorded their responses on forms that were given to them. This allowed us to remember all the themes evoked. At the same time, we took notes and transcribed all the discussed ideas. Afterwards, all of the responses were transcribed into an Excel table which constituted our database. 
A distinction is made between literal transcription (word for word) and partial transcription. In this study, we opted for a partial transcription which removed redundancies, eliminated digressions or parts that did not have an obvious connection with the research (Savoie-Zajc, 2009).

Once the corpus was constituted, we proceeded to the data coding and analysis. By coding, we mean the processes of transforming raw data into a standardized form (Babbie, 2016). The corpus was broken down into five major themes divided into units of analysis (Table 2). Themes were identified through a deductive process based on the theoretical framework and previous research (Mayring, 2014).

In order to ensure result fidelity and completeness and also to reduce the risk of researchers' subjectivity, we used the inter-coder reliability method which referred to the degree of agreement of different coders on the defined coding scheme (Dépelteau, 2000). We (both authors) independently proceeded to code texts using the same coding scheme, and at each divergence of opinion on certain points or elements, a common and logical solution was proposed.

\section{RESULTS AND DISCUSSION}

Table below shows different themes that emerged from the analysis and that represent the main barriers faced from the QAM perspective. Thus, the frequencies of occurrence of the themes and units were calculated. They indicate the number of times they were mentioned in the QAMs' speeches. This allowed measuring their importance.

Table 2. Interview Content Analysis Grid (developed by the authors)

\begin{tabular}{|c|c|c|c|c|}
\hline \multirow{2}{*}{ Themes } & \multirow{2}{*}{ Analysis units } & \multirow{2}{*}{ Frequency } & \multicolumn{2}{|c|}{ Theme } \\
\hline & & & No. & $\%$ \\
\hline \multirow{4}{*}{$\begin{array}{l}\text { Lack of resources } \\
\text { and insufficient } \\
\text { time allocated }\end{array}$} & Lack of material resources allocated & 9 & \multirow{4}{*}{19} & \multirow{4}{*}{40} \\
\hline & Lack of financial resources allocated & 4 & & \\
\hline & Lack of competent human resources & 1 & & \\
\hline & Insufficient time allocated & 5 & & \\
\hline \multirow{3}{*}{$\begin{array}{c}\text { Lack of } \\
\text { encouragement and } \\
\text { motivation of the } \\
\text { Project Teams }\end{array}$} & Non-encouragement of Project Teams & 6 & \multirow{3}{*}{11} & \multirow{3}{*}{23} \\
\hline & $\begin{array}{l}\text { Decreased/lack of motivation of QAMs } \\
\text { and Project Teams }\end{array}$ & 4 & & \\
\hline & $\begin{array}{l}\text { Little initiative taken by the Project } \\
\text { Teams }\end{array}$ & 1 & & \\
\hline \multirow{3}{*}{$\begin{array}{c}\text { Lack of } \\
\text { management } \\
\text { commitment }\end{array}$} & $\begin{array}{l}\text { Lack of management commitment and } \\
\text { involvement }\end{array}$ & 7 & \multirow{3}{*}{9} & \multirow{3}{*}{19} \\
\hline & Lack of management support & 1 & & \\
\hline & Instability of institution managers & 1 & & \\
\hline \multirow{3}{*}{$\begin{array}{c}\text { Roles and } \\
\text { responsibilities not } \\
\text { clearly defined } \\
\text { and/or not } \\
\text { formalized }\end{array}$} & $\begin{array}{l}\text { Insufficient prerogatives given to the } \\
\text { QAMs }\end{array}$ & 4 & \multirow{3}{*}{6} & \multirow{3}{*}{13} \\
\hline & Lack of formalization of the QAU's tasks & 1 & & \\
\hline & $\begin{array}{l}\text { Centralization of QA and self-assessment } \\
\text { activities }\end{array}$ & 1 & & \\
\hline \multirow{2}{*}{$\begin{array}{l}\text { Lack of clear } \\
\text { vision and goals }\end{array}$} & Lack of clear QA vision & 1 & \multirow{2}{*}{3} & \multirow{2}{*}{6} \\
\hline & Lack of clear goals (no quality charter) & 2 & & \\
\hline & Total & 48 & 48 & 100 \\
\hline
\end{tabular}


In the following, we will analyse and discuss the results obtained. The analysis will be supported and illustrated by verbatims extracted from the corpus (the transcribed speeches).

The QAMs interviewed will be coded "QAMnumber_Region".

\subsection{Lack of Resources and Time Allocated}

The QA implementation requires human, material, and financial resources. Nevertheless, the data analysis indicates a lack of allocated resources.

Several QAMs interviewed stated the lack of allocated financial resources as a barrier to the QA process. This finding is supported by the literature (Tari, 2010; Tari, 2011; Mishra \& Pandey, 2013/1). The RAQs believe that this budget would have allowed them to acquire the necessary means and to encourage and train the Project Teams. The following testimonial confirms this:

"Lack of budget to acquire the necessary material means, train the staff involved in the process, pay them and motivate them..." (QAM ${ }_{2}$ Centre)

A budget is therefore necessary, according to the QAMs, for the success of the QA project. This finding converges with the result obtained by Alzafari and Kratzer among quality experts who testified to the importance of financial resources in order to support the institution activities and to train and develop staff skills (Alzafari \& Kratzer, 2019).

This situation could be explained by the fact that Algerian HEIs are public, with limited financial autonomy, and operate with funds allocated by the government. HEI managers do not have sufficient autonomy to allocate and make available all the necessary resources for the functioning of the QA process, which is not institutionalized. In fact, there is no regulatory framework defining the attachment of QAUs within institutional structures (ESAGOV, 2020).

The first finding of this study is then the lack of budget allocated to QA. Removing this constraint is therefore more responsibility of the supervisory authority than the HEI management, as it is the supervisor who should define a clear policy, estimate the costs of the project and allocate the necessary funds.

In addition, the lack of material resources was a recurring point in the testimonies of QAMs, as confirmed by the following statements:

"Lack of material means that facilitate the work of the QAUs and SACs (Office, office furniture, computer equipment, internet connection ... etc.)" (QAM _West)

"We lack material means to carry out the different activities: an office to carry out the QA actions, to archive the files and evidence collected..." (QAM2_Centre)

From these testimonies, we conclude that the Project Teams have not been provided with all the means they need to accomplish their mission. Nevertheless, some resources were granted within the limits of those already available in the HEIs, or what we call resources at hand (as testified by $\mathrm{QAM}_{3}$ Centre). It seems that these resources were not sufficient to carry out the QA experiment.

Another barrier that hampered the QA process was the inadequate time given to conduct the quality self-assessment exercise. It was claimed by the QAMs that the time given was insufficient. This statement was particularly made by the QAMs of universities with a large size compared to other types of HEIs (schools and centres). They reported that the time spent on the operation was the same for all 
institutions regardless of their size or multidisciplinarity. This had a direct impact on the choice of the self-assessment scope (areas and entities).

Faced with this issue, the QAMs came under strong pressure from their institution managers. One QAM told us about the experience with her manager and the pressure she was under. She stated that this pressure caused her to resign from her job:

"The manager was putting a lot of pressure to beautify his image and meet the supervisory authority's request on time. We were working under pressure. I submitted my resignation from the QAM position because of him" (QAM4_Centre)

In a similar vein, another QAM shared an almost similar view:

"The director only thinks about the reports to be submitted to the supervisory authority. His goal is to submit them on time to the detriment of work to be done to prepare them" (QAM2_Centre)

This testimony reminds us of the phrase used by Mussawy and Rossman (2018) who characterised the QA processes as compliance to submit paperwork on time. This does seem to be the case at some institutions.

Finally, we conclude that QAMs lacked time, money, and resources to successfully implement QA. These constraining factors were confirmed by the literature.

\subsection{Lack of Encouragement and Motivation of Project Teams}

Most of the QAMs claimed the lack of financial recompense in view of new responsibilities assigned to the actors involved in the project (themselves and project teams). This is reflected in the following claims:

"The members of quality bodies have asked to be paid in view of their efforts. I told them that I, as a QAM, have not been paid..." (QAM $\left.M_{-} C e n t r e\right)$

"Members are not paid. Since 2011 I have been a QAM, I have not received anything to date..." (QAM4_Centre)

"No gratification or motivation is perceived by the QAM or the members in view of the tasks they are given" (QAM7_West)

According to one QAM (QAM ${ }_{2}$ Centre), the lack of incentives is logically due to the lack of budget. This has decreased the motivation of QAMs and project teams who are not encouraged to do QA-related work.

"The members were not really motivated, Mr. Former QAM was always reminding them of the dates set for meetings and sending in the requested work" (QAM3_Centre)

According to one QAM (QAM ${ }_{12}$ East), this lack of motivation led to a lack of initiative-taking by project teams.

From the discussions among the QAMs, we could conclude that the problem of the lack of financial rewards had a negative impact on involvement and motivation of the project teams. This demotivation seems warranted because QAMs, as academics, consider their salaries to be demotivating at the base. Hazlett \& Hill state that in the public sector there is already a general belief that staff are overworked and underpaid (Hazlett \& Hill, 2000). As a result, they reluctantly perform new tasks in the absence of compensation. 


\subsection{Lack of Management Commitment}

Several QAMs openly acknowledged the lack of management commitment and support for the self-assessment process, and for QA in general. Numerous expressions used by the QAMs confirm this observation: "management inertia", "resistance from institution managers", "disinterest of managers", "lack of belief in quality", "lack of commitment", "lack of involvement", "lack of support".

This seems surprising because all HEI managers were instructed to conduct the quality self-assessment exercise and to report to the supervisory authority. Their involvement was therefore inevitable.

In that context, the QAMs' statements led us to believe that the managers commitment was weak and insufficient. We assume that the Ministry did not give enough time to HEI managers to become aware of the complexity of the quality self-assessment process and the organisational changes needed to ensure its effectiveness (Ritchie \& Dale, 2000) (the operation was launched on 15 January 2017, and the deadline for reports submission was set for 6 July of the same year). HEI managers were then not sufficiently sensitized and trained to commit to and support the process. Hence, their commitment was weak, and it seemed to have been a barrier to the success of QA from the perspective of the QAMs. This finding is consistent with the literature (Ritchie \& Dale, 2000; Tari, 2010; Tari, 2011; Mulu, 2012; Hassan \& Fan, 2016).

The lack of management commitment made the work related to QA difficult, and greatly influenced the QAMs' perception of the process as a whole. We noticed this during the exchanges and interactions between them. The QAMs are unable to see the positive side of quality, because they believe that it will not bring anything without a strong commitment and a real belief on the part of the first managers.

We can therefore affirm that management support and commitment influence the perception of the effectiveness of quality by the QAMs. A strong correlation relationship between these two elements has already been demonstrated by (Seyfried \& Pohlenz, 2018). They made it clear that without the support of higher management, QM is a 'toothless tiger'.

Another barrier that is leadership instability and succession was reported by one QAM (QAM ${ }_{1}$ Centre). This seems to make sense because it involves making one change while another is in progress. Collerette mentioned that overly frequent changes (waves of change succeeding each other at a high rate, with no period of consolidation and respite) were among the practices that could negatively impact change (Collerette, 2008). QA is already a change project that requires the stability of other elements to succeed, including management support and commitment throughout the implementation process. Therefore, management instability negatively affects the entire QA process.

Previous studies have demonstrated similar results. Mulu reported that leadership turnover was likely to hinder the adoption of QI systems and lead to unfavourable outcomes (Mulu, 2012). However, we assume that this remains relative, as not all HEIs have had a change in management during the QA implementation. 


\subsection{Failure to Define Roles and Responsibilities}

QAMs reported insufficient prerogatives given to the QAU. The following recurring expressions confirm the finding: "QAU has no decision-making authority", "QAU prerogatives and relationship with others structures not defined", "QAU lacks authority".

This constraint seems to have existed since the launch of the QA project. Almost nearly ten years later, the responsibilities of QAU members are not clearly defined. Moreover, the QAMs are not involved in decision making that affects their institutions and do not have all the prerogatives to ensure their missions.

This could be explained by the non-institutionalization of the QA process. The QAUs have no official status or position in the HEI organizational charts, and therefore no legitimate role that gives them authority and prerogatives.

\subsection{Lack of Clear Vision and Goals}

The lack of vision and goals setting was reported. This barrier is ranked last according to the degree of importance given by QAMs (Table 2). The reason is that QAMs think that the goals are set by the Ministry, and therefore this did not seem to hinder the process.

For the QAMs, the QA goal was to assess the compliance of practices with the national standard criteria and to report the results within the deadlines. It seems therefore that compliance was a more pressing concern than the improvement of practices.

\section{CONCLUSION}

The empirical results and the analysis performed have allowed the authors to make the following conclusions:

The main barrier to QA is related to the limitations of HEI governance which do not promote autonomy and effectiveness. The limited autonomy (in the sense of lack of independence in action) granted to institution managers has been a notable constraint. The involvement of managers in QA processes was inevitable in order to meet the demands of the supervisory authority. However, it remains weak and insufficient in the absence of autonomy and independence.

HEI managers have not been able to allocate and make available all the resources needed to implement QA, especially financial resources which are allocated by the government in the form of a budget. However, the QA process is not institutionalized. This has had a significant negative impact on the process, particularly on the implementation of important actions requiring funding, such as training, awareness-raising and motivation of internal actors.

In addition to limited resources, another important constraint was the length of time granted by the Ministry to conduct the self-assessment. The results showed that this time frame was insufficient because the HEIs were not prepared to carry out this new activity in such a short time frame. Pressure was therefore exerted on the HEI managers, who in turn exerted pressure on the actors in charge of QA, particularly the QAMs. 
As a result, the most pressing objective of the HEIs was to verify compliance with the RNAQES rather than to improve practices. The achievement of this objective was entrusted to the bodies in charge of QA without their status, prerogatives, roles and missions being clearly defined and formalized.

These constraints indicate a lack of leadership in all dimensions of the (Middlehurst, 1997) framework. In the conceptual and analytical dimension, managers did not set or communicate clear goals related to QA. Thus, their commitment was weak and transmitted to the rest of the staff. In the second structural and systemic dimension, structures and bodies in charge of QA were created but their functions and responsibilities were not clearly defined. In the last motivational and behavioural dimension, the demotivation of internal actors was declared, especially those directly involved in the implementation of the project.

Based on the analysis and discussion of the results, we propose considering two main barriers to the implementation of QA in Algeria, i.e.: limited leadership and lack of training and awareness among institution managers. We believe that these two elements could be at the root of the success or failure of QA approaches. They are closely related and complementary. If HEI managers are given autonomy, they can allocate all the necessary resources and motivate and train internal actors. However, they themselves must be trained, aware and convinced of the importance of QA in order to better commit to the process and devote time, energy and specific budget to it.

In conclusion, our study, like any research study, has some limitations. First, it focuses on public HEIs because the private sector has emerged recently, and has a small number of establishments that were not concerned by the QA project. Second, the work focused on a single stakeholder, namely the QAMs. It would be useful in future research to extend the survey to other internal and external stakeholders.

\section{REFERENCES}

Ahmed, A., Yang, J., \& Dale, B. (2003). Self-Assessment Methodology: The Route to Business Excellence. Quality Management Journal, 10(1), 43-57. https://doi.org/10.1080/10686967.2003.11919052

Alzafari, K., \& Kratzer, J. (2019). Challenges of implementing quality in European higher education: an expert perspective. Quality in Higher Education, 25(3), 261-288. https://doi.org/10.1080/13538322.2019.1676963

Ary, D., Lucy Cheser J.,Chris S., A. Razavieh (2014). Introduction to research in education. Cengage Learning.

Babbie, E. (2016). The practice of social research. Fourteenth Edition. . Cengage Learning.

Bardin, L. (1977). L'analyse de contenu. Paris, PUF.

Bryman, A. (1992). Charisma and Leadership in Organisations. London: Sage.

Campbell, C., \& Rozsnyai, C. (2002). Quality Assurance and the Development of Course Programmes. Papers on Higher Education.

Collerette, P. (2008). Pour une gestion du changement disciplinée dans l'administration publique. In revue Télescope, 14(3), 33-49.

Dépelteau, F. (2000). La démarche d'une recherche en sciences humaines: De la question de départ à la communication des résultats. Presses Université Laval.

Elassy, N. (2015). The concepts of quality, quality assurance and quality enhancement. Quality Assurance in Education, 23(3), 250-261. https://doi.org/10.1108/QAE-11-2012-0046 
ESAGOV. (2020). L'Enseignement Supérieur Algérien à l'heure de la Gouvernance Universitaire. RAPPORT Final WP1 - Préparation et recherche. Récupéré sur https://esagovproject.eu/wpcontent/uploads/2020/07/ESAGOV_Rapport_WP1.pdf

Gordon, G., \& Whitchurch, C. (2007). La gestion des ressources humaines dans l'enseignement supérieur : la diversification des fonctions et ses conséquences. Politiques et gestion de l'enseignement supérieur, 2(2), 151-175. https://doi.org/10.1787/hemp-v19-art14-fr

Harvey, L., \& Newton, J. (2004). Transforming quality evaluation. Quality in Higher Education, 10(2), 149-165. https://doi.org/10.1080/1353832042000230635

Hassan, A., \& Fan, S. (2016). Obstacles Hindering TQM Implementation in Secondary Schools in Saudi Arabia. International Conference on Education and New Developments. 12 Juin.

Hazlett, S.-A., \& Hill, F. (2000). Policy and Practice: An Investigation of Organizational Change for Service Quality in the Public Sector in Northern Ireland. Total Quality Management, 11(46), 515-520. https://doi.org/10.1080/09544120050007832

Hou, A. Y.-C., Ince, M., Tsai, S., \& Chiang, C. L. (2015). Quality assurance of quality assurance agencies from an Asian perspective: regulation, autonomy and accountability. Asia Pacific Education Review, 16(1), 95-106. https://doi.org/10.1007/s12564-015-9358-9

Koch, J., \& Fisher, J. (1998). Higher education and total quality management. Total Quality Management, 9(8), 659-668. https://doi.org/10.1080/0954412988136

Martin, M., \& Stella, A. (2007). External quality assurance: options for higher education managers: IIEP training modules- Module 1: Making Basic Choices for External Quality Assurance Systems. International Institute for Educational Planning, UNESCO.

Mayring, P. (2014). Qualitative content analysis: theoretical foundation, basic procedures and software solution. Récupéré sur https://nbn-resolving.org/urn:nbn:de:0168-ssoar-395173. https://doi.org/10.1007/978-94-017-9181-6 13

Middlehurst, R. (1997). Reinventing Higher Education: the leadership challenge. Quality in Higher Education, 3(2), 183-198. https://doi.org/10.1080/1353832970030208

Mishra, P., \& Pandey, A. (2013/1). Barriers in implementing total quality management in Higher Education. Journal of Education \& Research for Sustainable Development, 1(1), 1-11.

Mishra, P., \& Pandey, A. (2013/2). The Role of Leadership in Implementing Total Quality Management (TQM) in Higher Education: A Review. European Academic Research, 1(8), 2149-2166.

Mulu, N. (2012). Quality and Quality Assurance in Ethiopian Higher Education: Critical Issues and practical implications. PHD thesis. University of Twente, Pays Bas.

Mussawy, S. A., \& Rossman, G. B. (2018). Quality Assurance and Accreditation in Afghanistan: Faculty Members' Perceptions from Selected Universities. Higher Learning Research Communications, 8(2), 9-34. https://doi.org/10.18870/hlrc.v8i2.411

Nguyen, H. (2016). Quality assurance in higher education in Vietnam: A case-study. . Doctoral dissertation, The College of Education, Victoria University.

O'Mahony, K., \& Garavan, T. (2012). Implementing a quality management framework in a higher education organisation. Quality Assurance in Education, 20(2), 184-200. https://doi.org/10.1108/09684881211219767

Pham, H., \& Starkey, L. (2016). Perceptions of higher education quality at three universities in Vietnam. Quality Assurance in Education, 24(3), 369-393. https://doi.org/10.1108/QAE-072014-0037

Ritchie, L., \& Dale, B. (2000). Self-assessment using the business excellence model: A study of practice and process. International Journal of Production Economics, 66(3), 241-254. https://doi.org/10.1016/S0925-5273(99)00130-9

Roskosa, A., \& Stukalina, Y. (2018). Management of a study programme in the context of quality assurance in higher education. In The Proceedings of the International Scientific Conference Rural Environment. Education. Personality (REEP), 11, 118-127. https://doi.org/10.22616/REEP.2018.014

Saurbier, A. (2020). A question of value: exploring perceptions of higher education value in academic and popular literature. Economics and Culture, 17(1), 62-74. https://doi.org/10.2478/jec-2020-0006 
Savoie-Zajc, L. (2009). L'entrevue semi-dirigée. In Gauthier, B. Recherche sociale: de la problématique à la collecte des données, 339-360, 3e éd, Québec, Presses de l'Université du Québec.

Sayeda, B., Rajendran, C., \& Lokachari, P. (2010). An empirical study of total quality management in engineering educational institutions of India. Benchmarking: an international journal, 7(5), 728-767. https://doi.org/10.1108/14635771011076461

Scharager Goldenberg, J. (2017). New actors in an old scenario: the professionalization of academic quality management in Chile, 1990-2015 (Translated from Spanish). Thesis in order to obtain the degree of Doctor at the University of Leiden.

Seyfried, M., \& Pohlenz, P. (2018). Assessing quality assurance in higher education: quality managers' perceptions of effectiveness. European Journal of Higher Education, 8(3), 258-271. https://doi.org/10.1080/21568235.2018.1474777

Tari, J. (2010). Self-assessment processes: the importance of follow-up for success. Quality Assurance in Education, 18(1), 19-33. https://doi.org/10.1108/09684881011015972

Tari, J. (2011). Similarities and differences between self-assessment approaches in public services in higher education institutions. The Service Industries Journal, 31(7), 1125-1142. https://doi.org/10.1080/02642060903295644

Torre, D., \& Zapata, G. (2012). Impacto de procesos de aseguramiento de la calidad sobre las instituciones de educación superior : un estudio en siete países. In Lemaitre, M.J. Aseguramiento de la Calidad en Iberoamérica. Educación Superior, 117-153. CINDA.

Venkatraman, S. (2007). A framework for implementing TQM in higher education programs. Quality Assurance in Education, 15(1), 92-112. https://doi.org/10.1108/09684880710723052

Welzant, H., Schindler, L., Puls-Elvidge, S., \& Crawford, L. (2015). Definitions of quality in higher education: A synthesis of the literature. Higher Learning Research Communications, 5(3), 3-13. https://doi.org/10.18870/hlrc.v5i3.244

Westerheijden, D. (2007). States and Europe and Quality of Higher Education. In D. F. Westerheijden, B. Stensaker \& M. J. Rosa (Eds.). Quality Assurance in Higher Education: Trends in Regulation, Translation and Transformation, 73-95. https://doi.org/10.1007/978-14020-6012-0 3

World Banque. (2012). Rapport sur la gouvernance des universités en Algérie. Récupéré sur http://wbgfiles.worldbank.org/documents/hdn/ed/saber/supporting_doc/Background/TED/SAB ER_TED_University_governance_Algeria.pdf

Zumitzavan, V., \& Michie, J. (2015). Personal knowledge management, leadership styles, and organisational performance: A case study of the healthcare industry in Thailand. Singapore: Springer. https://doi.org/10.1007/978-981-287-438-2

\section{AUTHORS' SHORT BIOGRAPHIES}

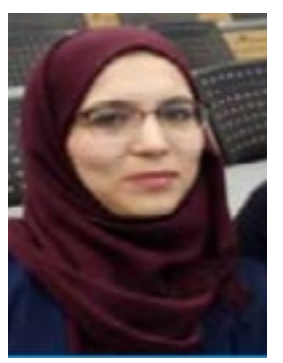

Wissam Belimane is a teacher and $\mathrm{PhD}$ student on quality management at ENSM Algeria. Her research work focuses on quality and assessment in higher education (at the time of publication). She is a member of the Public Management Research Laboratory at ENSM (LIMGE) and of Self-Assessment Committee (ENSV) at ENSV.

E-mail: belimane.wissam@gmail.com / w.belimane@ensm.dz ORCID iD: https://orcid.org/0000-0003-2302-0031

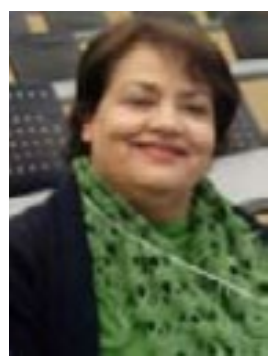

Amina Chahed, $\mathrm{PhD}$, is a Lecturer " $\mathrm{A}$ " at ENSV Algeria, and Freelance Consultant Trainer. She specialises in food safety and quality management, and she is a certified ISO 9001 and ISO 22000 third party auditor. Her main research interests and publications are in the agrifood, veterinary and quality assurance fields. She is a member of the Commission for the Implementation of Quality Assurance in Higher Education (CIAQES) and the Quality Assurance Manager (QAM) at ENSV.

E-mail: a.chahed12@gmail.com 